\title{
PERFIL DE PRODUTORES FRENTE À VACINAÇÃO CONTRA DOENÇAS INFECCIOSAS ABORTIVAS EM REBANHOS BOVINOS DO MUNICÍPIO DE ALEGRE/ES
}

\section{Profile of producers faces vaccination against infectious diseases that causes abortion in cattle of municipality Alegre/ES, Brazil}

\author{
VIANA, K.F. ${ }^{1}$; ZANINI, M.S. ${ }^{2}$ \\ 1 Programa de Pós Graduação em Biotecnologia, Universidade Federal de Ouro Preto \\ ${ }^{2}$ Professor do Departamento de Medicina Veterinária - DMVET, Universidade Federal do Espírito Santo \\ Endereço para correspondência: Kelvinson Fernandes Viana: kelvinsonviana@yahoo.com.br
}

\section{RESUMO}

A sanidade do rebanho assume um papel de fundamental importância em qualquer que seja o sistema de exploração. Ações como, prevenção contra novas doenças; redução da exposição do rebanho às enfermidades e aumento do nível de resistência do rebanho, contribui para que o sistema imunológico do bovino obtenha condições suficientes para funcionar adequadamente. A prevenção contra doenças infecciosas causadoras de aborto como brucelose, leptospirose, campilobacteriose, tricomonose, neosporose, IBR e BVD, torna-se fundamental para o proprietário conseguir sucesso no sistema de produção. Este trabalho visou verificar o conhecimento de produtores de gado de leite frente à vacinação contra doenças infecciosas causadoras de aborto em bovinos, assim como o risco zoonótico de algumas dessas enfermidades. Um total de 30 propriedades foram visitadas e aos proprietários, foi submetido um questionário sobre o conhecimento de doenças abortivas em bovinos, assim como, programas de vacinação do rebanho contra as doenças acima citadas, obtendo-se os seguintes resultados: 12 propriedades vacinavam contra brucelose, sendo que dentre elas, 2 vacinavam também contra leptospirose; as 18 propriedades restantes não faziam vacinação contra nenhuma das enfermidades. Dois proprietários tinham conhecimento que todas as doenças causavam aborto e 28 proprietários sabiam que apenas a brucelose causava aborto. A falta de informação por parte dos produtores rurais ainda é um obstáculo quanto à sanidade do rebanho, sendo necessário fomento que busque divulgar as informações para que os mesmos possam utilizá-las, contribuindo para o aumento da produtividade de rebanhos leiteiros.

Palavras-chave: aborto; campilobacteriose; leptospirose; neosporose; tricomonose

\begin{abstract}
The health of the herd takes a role of great importance in whatever operating system. Actions such as prevention against new diseases, reduction of exposure to diseases of the herd and increasing the resistance level of the herd, which helps the immune system of cattle get sufficient conditions to function properly. The prevention of infectious diseases as causes of abortion, brucellosis, leptospirosis, campylobacteriosis, tricomonosis, neosporosis, IBR and BVD, it is crucial to the owner achieve success in your production system. This study aimed to verify the knowledge of producers of dairy cattle in front of vaccination against infectious cause of abortion in cattle as well the risk of some zoonotic diseases. A total of 30 properties were visited and the owners submitted a questionnaire about their knowledge of diseases in cattle abortion, as well as programs for vaccination of cattle against diseases mentioned above. It was yielding the following results: 12 properties vaccinated against brucellosis, being among them, 2 vaccinated against leptospirosis, the 18 remaining properties were not vaccinate against any of the diseases, 2 owners were aware that all diseases caused abortion and 28 owners knew that only the brucellosis caused abortion. The lack of information from farmers is still an obstacle on the health of the cattle, but need encouragement to disseminate necessary information so that they can use them, helping to increase the quality of the final product.
\end{abstract}

Key words: abortion; campylobacteriosis; leptospirosis; neosporosis; tricomonosis 


\section{INTRODUÇÃO}

O cenário atual da pecuária leiteira, que coincide com tendências também verificadas em outras atividades agropecuárias, é a redução do número das unidades de produção (vacas leiteiras) e o aumento da produtividade (volume de leite por lactação) (Hayirli et al., 2002). Entretanto, o aumento da produtividade tem sido associado à maior incidência de enfermidades, que podem levar a prejuízos econômicos para o produtor, maiores riscos de presença de resíduos de antibióticos no leite e uma percepção negativa da atividade leiteira junto à população (Grummer, 1995).

Um programa de saúde animal consiste no planejamento de atividades veterinárias regularmente aplicadas e do bom manejo do rebanho para a manutenção da saúde animal e produtividade em níveis ótimos (Radostits e Blood, 1986). O estudo de programas de saúde animal para a prevenção de enfermidades em sistemas de produção leiteira em nossas condições zootécnicas e climáticas deve ser estimulado. Doenças infecto-contagiosas da reprodução animal como a Rinotraqueíte Infecciosa Bovina (IBR), Diarréia Viral Bovina (BVD), Brucelose e Leptospirose, estão disseminadas no rebanho nacional, havendo necessidade de preveni-las (Del Fava et al., 2003).

Este trabalho visou obter o perfil de produtores de gado de leite frente à vacinação contra as seguintes doenças causadoras de abortamento: Brucelose, Leptospirose, Campilobacteriose, Tricomonose, Neosporose, Rinotraqueíte infecciosa bovina e Diarréia viral bovina em rebanhos bovinos do município de Alegre, sul do estado do Espírito Santo, assim como o conhecimento do potencial zoonótico das enfermidades em questão.

\section{MATERIAL E MÉTODOS}

O presente trabalho foi realizado na microrregião do Caparaó, sul do Espírito Santo durante o período de março a dezembro de 2007. A partir de uma listagem de propriedades produtoras de leite, cadastradas no Instituto de Defesa Agropecuária e Florestal (IDAF) do município, foram selecionadas 30 propriedades rurais pelo critério de proximidade com o Centro de Ciências Agrárias da Universidade Federal do Espírito Santo.

Aos produtores foi submetido um questionário sobre o sistema de produção praticado, conhecimento de algumas doenças causadoras de abortamento em bovinos (Brucelose, Leptospirose, Campilobacteriose, Tricomonose, Neosporose, Rinotraqueíte infecciosa bovina e Diarréia viral bovina), programas de vacinação e potencial zoonótico das enfermidades. Em nenhuma das propriedades havia mais de 100 animais, sendo predominante em todas as propriedades, as raças Holandês e Girolando.

\section{RESULTADOS E DISCUSSÃO}

Das 30 propriedades rurais avaliadas, 12 propriedades vacinavam contra brucelose, sendo que dentre elas, 2 vacinavam também contra leptospirose; as 18 propriedades restantes não faziam vacinação contra nenhuma das enfermidades avaliadas. Apenas dois proprietários tinham conhecimento que todas as doenças causavam aborto em bovinos, além de terem conhecimento dos riscos que cada uma poderia trazer à saúde humana, e 28 proprietários apenas sabiam que a brucelose causava abortamento nos animais, desconhecendo qualquer informação dos riscos de transmissão para o homem. A atenção profilática em $100 \%$ das propriedades foi direcionada à febre aftosa. 
Em todas as propriedades visitadas a área variou de 5 a 10 alqueires, sendo classificadas como de pequeno porte. $O$ sistema de criação predominante era 0 extensivo, e em nenhuma propriedade havia mais de 40 vacas em lactação, sendo a média geral de 200 litros de leite ao dia. Ordenha mecanizada e inseminação artificial eram usadas em apenas duas propriedades, predominando o uso de touros para monta natural e ordenha manual nas demais. Em geral, a atividade leiteira não era única, estando quase sempre em associação com a cultura de café.

Em decorrência da escassez de dados referentes às perdas reprodutivas em rebanhos bovinos pelas enfermidades estudadas na região, torna-se complexo detalhar a taxa de abortamentos ocorridos na área por conseqüência destes agentes infecciosos, possivelmente por falta de ocorrência ou diagnóstico. Os resultados obtidos são apresentados nas figuras 1, 2 e 3 .

É de extrema importância que os produtores rurais saibam as formas de transmissão e os riscos de contrair zoonoses. Em relação à brucelose bovina, as fontes mais comuns de contaminação são os fetos abortados, os envoltórios fetais, as descargas vaginais de fêmeas infectadas, a água, os alimentos e fômites contaminados (Vanzini et al., 1997; Bercovich, 1998; Maurício e Coast, 1998). $\mathrm{Na}$ leptospirose, a fonte de infecção para o rebanho pode ser um animal infectado, que contamina água, alimentos e pastagens, através de sua urina, fetos abortados e descargas uterinas (Radostitis et al., 1994). O ideal seria fazer sorologia dos animais para ter conhecimento dos sorovares que circulam no rebanho e, a partir desses dados, usar uma vacina autógena com os próprios sorovares diagnosticados. Porém, na maioria das vezes, os proprietários adquirem vacinas comerciais que nem sempre contém as amostras apresentadas pelos animais, 0 que reduz o sucesso da profilaxia da doença no rebanho, e, consequentemente, as leptospiras continuam causando transtornos de produção e reprodução nos bovinos.

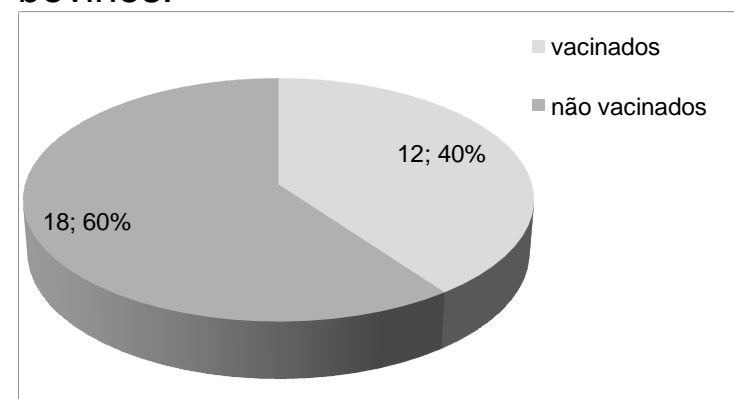

Figura 1 - Percentual de propriedades entrevistadas que vacinavam contra brucelose bovina.

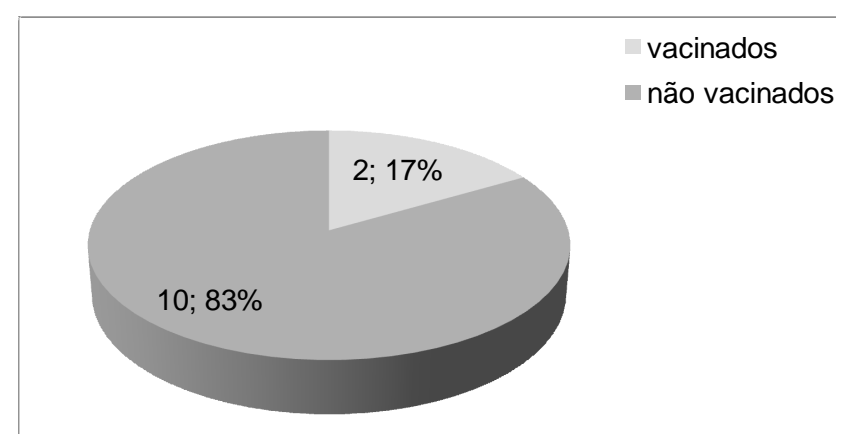

Figura 2 - Percentual de propriedades onde havia vacinação contra leptospirose bovina em relação ao total de 12 propriedades que realizavam vacinação contra pelo menos uma doença.

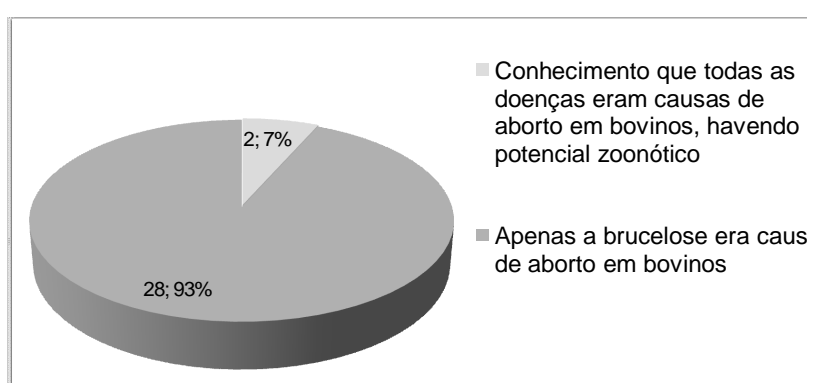

Figura 3 - Percentual de produtores rurais que sabiam do potencial zoonótico de todas as enfermidades em questão, assim como os prejuízos que poderiam trazer à reprodução dos bovinos.

As bactérias do gênero Campylobacter são causa importante de doenças no homem, sendo relatadas ambas as subespécies de $\mathrm{C}$. fetus em sangue de humanos com septicemia, ocasionando 
infecções oportunistas extra intestinal (Wang et al., 1993; Blaser et al.,1994; Dworkin et al., 1995). Uma prática muito comum na pecuária leiteira nacional, que representa um potencial risco para a transmissão da Campilobacteriose genital bovina e da Tricomonose bovina em rebanhos onde se utiliza a inseminação é o chamado touro de repasse. Embora não existam registros, estima-se que o touro de repasse seja utilizado em pelo menos $50 \%$ das pequenas e médias propriedades (Garcia e Brooks, 1993). E importante ressaltar que no presente estudo, o touro de repasse só não era usado nas duas propriedades em que era realizada a inseminação artificial, sendo uma prática comum em grande parte das propriedades rurais brasileiras.

O Herpesvírus Bovino tipo 1 (HVB-1) é - agente causador da Rinotraqueíte Infecciosa Bovina/ Vulvovaginite Pustular Infecciosa Bovina (IBR/IPV) (Roizman et al., 1995). A via de transmissão direta horizontal é a mais importante e ocorre através do contato direto entre os animais e também pela cópula, porém o embrião e feto podem infectar-se pela via vertical (transplacentária). A transmissão indireta ocorre principalmente por aerossóis e fômites, tendo a inseminação artificial importante papel na entrada da doença em rebanhos que nunca tiveram contato com o vírus. O principal fator na disseminação natural do vírus da BVD é a existência de um animal persistentemente infectado (PI) (Lemaire et al., 1994). Programas de controle e erradicação da infecção pelo BVDV sem o uso de vacinas têm sido implementados em alguns países europeus e são baseados na identificação de rebanhos infectados, descarte dos animais $\mathrm{PI}$ e certificação de rebanhos livres (Lindberg e Alenius, 1999).

A tricomoníase caracteriza-se principalmente, por induzir metrite catarral ou purulenta, que acarreta mortes embrionárias ou abortos, principalmente no início da gestação. As lesões fetais não são específicas, mas grande número de protozoários podem ser observados nos fluidos e no estômago fetal (Riet-Corrêa et al., 2003).

O desconhecimento atual sobre a prevalência e epidemiologia da Tricomonose Bovina em nosso meio e, consequentemente, sobre sua importância econômica, leva a situações graves como a ausência no mercado nacional de drogas para o tratamento específico dos animais infectados. Estima-se que apenas 3,8\% do rebanho nacional é submetido à inseminação artificial (Volta, 1996). Os trabalhos mais recentes indicam que a vacinação pode ser uma alternativa complementar para o controle, não descartando os outros aspectos de teste, descarte seletivo e reposição de touros, entre outros (Hall et al.,1993; Gault et al., 1995).

Em relação à neosporose, bovinos infectam-se através da ingestão de oocistos (Barr, 1998). Há evidências da transmissão transplacentária de Neospora caninum em bovinos de leite, sugerindo que infecções pelo protozoário podem persistir dentro de uma propriedade leiteira (Anderson et al., 1997). Estudos sobre desenvolvimento de vacinas estão sendo realizados por laboratórios e centro de pesquisa, e atualmente no Brasil já existe uma vacina comercial inativada de $\mathrm{N}$. caninum que, em um estudo de campo, demonstrou ser eficaz na redução do índice geral de abortamentos (Bielsa et al., 2004).

A necessidade de informação frente a estas enfermidades não está relacionada apenas às baixas no índice de fertilidade dos rebanhos, mas também nos riscos que algumas delas podem trazer à saúde dos próprios trabalhadores que lidam diariamente com animais infectados, sendo que investimentos em biossegurança tornam-se necessários para minimizar a exposição aos riscos de contrair doenças. Entretanto, nem sempre a biosseguridade é uma conduta bem recebida pelos 
pecuaristas e por técnicos do setor, pois prevê um sistema de produção leiteira fechado.

Necessita ser esclarecido que a biossegurança prevê a adoção de um conjunto de medidas e seus benefícios já foram comprovados não somente para atingir a erradicação, mas também para manter a propriedade livre de doenças infecciosas em populações animais (Gonçalves, 1990; Côrtes, 1993).

\section{CONCLUSÕES}

O fato da vacinação contra a brucelose ser maior quando comparada às demais doenças decorre do Programa Nacional de Controle e Erradicação da Brucelose e da Tuberculose Animal - PNCBT.

Faltam informações básicas de manejo sanitário visando a prevenção de problemas reprodutivos causados por agentes infecciosos. A falta de informação por parte dos produtores rurais caracterizou-se como fator primordial para a não-vacinação dos animais.

\section{REFERÊNCIAS}

ANDERSON, M. L.; REYNOLDS, J. P.; ROWE, J. D. et al. Evidence of vertical transmission of Neospora sp. infection in dairy cattle. Journal of the American Veterinary Medical Association, v.210, p.1169-1172, 1997.

BARR, B. C. Question: What is neosporosis? (Suplement to Compendium on Continuing Education for the Practicing Veterinarian, 1998). Veterinary Exchange, v.20, n.11, p.4, 1998.

BIELSA, J. M.; ROMERO, J. J.; HEUER, C. Controle de Neosporose em bovinos com Bovilis Neoguard: a experiência de campo. Revista Brasileira de Parasitologia Veterinária, v.13, suplemento 1, 2004.

BLASER, M. J.; WANG, E.; TUMMURU, M. K. et al. High-frequency SLP protein variation in Campylobacter fetus revealed by sapA mutagenesis. Molecular Microbiology, v.14, n.3, p.453-462, 1994.

BERCOVICH, Z. Maintenance of Brucella abortus free herds: a review whith emphasis on the epidemiology and the problems in the diagnosing brucellosis in areas of low prevalence. The Veterinary Quarterly, v.20, n.2, p.81- 88, 1998.

CÔRTES, J. D. (Ed.) Epidemiologia: conceitos e princípios principais. São Paulo: Varela, 1993. 227p.

DEL FAVA, C.; ARCARO, J. R. P.; POZZI, C. R. et al. Manejo sanitário para o controle de doenças da reprodução em um sistema leiteiro de produção semi-intensivo. Arquivos do Instituto Biológico. São Paulo, v.70, n.1, p.25-33, 2003.

DWORKIN, J.; TUMMURU, M. K.; BLASER, M. J. A lipopolysaccharide-binding domain of the Campylobacter fetus SLP protein resides within the conserved $\mathrm{N}$ terminus of a family of silent and divergent homologs. Journal of Bacteriology, v.177, n.7, p.1734-1741, 1995.

GARCIA, M. M.; BROOKS, B. W. Campylobacter. In: PRESCOTT, J.F.; ZUERNER, R.L.; GYLES, C.L. et al. (Ed.). Pathogenegis of bacterial infections in animals. 2. ed. Ames: lowa State University Press, 1993. p.262-272.

GAULT, R. A.; KVASNICKA, W. G.; HANKS, D. et al. Specific antibodies in serum and vaginal mucus of heifes inoculate with a vaccine containing Trichomonas foetus. American Journal of Veterinary Research, v.56, n.4, p.454-459, 1995.

GONÇALVES, E. I. (Ed.) Manual de Defesa Sanitária Animal. Jaboticabal: FUNEP, 1990. $133 p$.

GRUMMER, R. R. Impact of changes in organic nutrient metabolism on feeding the transition dairy cow. Journal Animal Science, v.73, p.2820-2833, 1995.

HALL, M.; KVASNICKA, W. G.; HANKS, D. et al. Improved control of trichomoniasis with Trichomonas foetus vaccine. Agri-practice, v.14, n.1, p.29-34, 1993.

HAYIRLI, A.; GRUMMER, R. R.; NORDHEIM, E. V. et al. Animal and dietary factors affecting feed intake during the prefresh transition period in Holsteins. Journal Dairy Science, v.85, p.34303443, 2002.

LEMAIRE, M.; PASTORET, P. P.; THIRY, E. Le contrôle de l'infection pas le virus de la rhinotrachéite infectieuse bovine. Annales Médecine Vétérinaire, v.138, n.3, p.167-180, 1994.

LINDBERG, A.; ALENIUS, S. Principles for eradication of bovine viral diarrhoea virus (BVDV) infections in cattle populations. Veterinary Microbiology, v.64, p.197-222, 1999.

MAURíCIO, R.; COAST. P. A brucelose animal: revisão bibliográfica. Veterinária Técnica, v. 32, n.2, p.46-53, 1998. 
RADOSTITS, O. M. \& BLOOD, D. C. (Ed.) Manual de controle da saúde e produção dos animais. São Paulo: Editora Manole, 1986. 530p.

RADOSTITIS, O. M; BLOOD, D. C; GAY, C. C. Veterinary Medicine. 8. ed., London: BalliéreTindall, 1994. $1736 \mathrm{p}$.

RIET-CORRÊA, F.; SCHILD, A. L.; MÉNDEZ, M. D. et al. Doenças de ruminantes e equinos. São Paulo: Editora Varela, 2003. 354p.

ROIZMAN, B.; DESROSIERS, R. C.; FLECKENSTEIN, B. et al. Family Herpesviridae. Archives of Virology, v.140, n.10, p.114-127, 1995.
VANZINI, V.; ECHAIDE, S. T.; LUGARESI, C. et al. Estrategias para el control y prevencion de la Brucelosis bovina en estabelecimentos lecheros. Temas de produccion lechera. INTA, n.84, 1997.

VOLTA, M. A. Inseminação artificial faz parte do futuro do país. Revista Brasileira de Reprodução Animal, v.20, n.3/4, p.91, 1996.

WANG, E.; GARCIA, M. M.; BLAKE, M. S. et al. Shift in $S$ Layer protein expression responsible for antigenic variation in Campylobacter fetus. Journal of Bacteriology, v.175, n.16, p.4979-4984, 1993. 